\title{
An Eclectic Credit Cycle Search: The Case of US, Japan and Germany
}

\author{
Athanasios L. Athanasenas ${ }^{1,2}$
}

\begin{abstract}
:
Credit crunches, quantitative easing and especially international credit cycles are all monetary facets of the still ongoing global economic crisis and financial turmoil. This paper investigates global credit cycle fundamental characteristics, among three leading economies; that is, the USA, Japanese and German.
\end{abstract}

Our statistically sophisticated time series data come from the Bank of International Settlements (BIS) open source. These valuable data cover the period of complete time series, from 1970(Q1) up to 2015(Q1), covering the whole data availability period for these three economic leaders. We indicate that during the 70's and the first decade of the $21^{\text {st }}$ century, we face significant statistical evidence that credit supply shocks in particular, in economies that lead capitalism globally, affect each other economy quite seriously.

The credit data confirm more the presence of an international credit cycle, in the sense that credit growth rates, in these three leading economies in particular, move together over time. We also verify, through classic impulse response analysis, that US credit supply shocks have a stronger effect upon the Japanese and German credit supply variable, for both the 1973 and most significantly the 2008 financial crisis years.

Key Words: Global Credit Cycles, VAR, BIS

JEL Classification: C32, E51, F39

\footnotetext{
${ }^{I}$ Department of Business Administration, School of Administration \& Economics, Central Macedonia Institute of Technology \& Education - Serres; Terma Magnesias Str. 621-24, Serres, Greece; Tel.: +302321049261; Fax: +302321049165; e-mail address: athans@teicm.gr;

${ }^{2}$ Acknowledgements This work bears heavy intellectual debts, once again, on Christopher Albert "Chris" Sims, the Nobel Memorial Prize in Economic Sciences winner in 2011, for his unforgettable inspiration and teaching at Minnesota during the 80's. Special thanks are due to the BIS for providing on line all initial credit time series data and the Federal Reserve Bank of St. Louis, Missouri, US, for providing on line all indices and deflators, used in this research. Appreciation is also expressed, once again, to the participants at the "old now" $14^{\text {th }}$ International Conference, 1-4 July, 2007, Thessaloniki, Greece, of the Multinational Finance Society (Rutgers University, University of Macedonia and Aristotle's University), where both, the "credit cycle research issue" along with the current global crisis, began to materialize. Special thanks are also due to Dr. K. Katrakilidis, AUTH, for continuous and excellent cooperation always.
} 


\section{Introduction}

Our research is concerned with the occurrence and transmission of specific credit supply shocks among three leading advanced economies; that is, the US, Japanese and German economies, in order to identify possible global credit cycles, along the credit - view $(\mathrm{CV})$ - credit easing $(\mathrm{CE})$ and the modern quantitative easing $(\mathrm{QE})$ economic doctrines. We are considering a trivariate VAR of credit to private nonfinancial borrowing sector of the USA, Japan and, Germany, with all the most recent time series credit data from the Bank of International Settlements (BIS) open source $^{3}$.

This eclectic VAR can be used to examine questions concerning the global transmission and generation of international credit cycles, among economic leaders worldwide. In particular, we try to identify whether international credit cycles, relating specific leading economies, are due to the transmission of independently generated credit shocks, or if they are due to common shocks contemporaneously impinging on these particular economies. It is well known that VAR's model linearity is very transparent and analytically tractable. This VAR qualification remains substantial for interpretation of results.

Our motive stems from the fact that in 2008, a series of bank and insurance company failures in US, triggered a serious financial crisis that effectively halted global markets and required unprecedented government intervention, first in US and second in the European Union. These failures caused a tremendous confidence crisis that made banks reluctant to lend money amongst themselves or to any over-indebted country (e.g. Greece, Portugal, etc.). Additionally, the recent credit crisis has had a staggering impact on the financial services sector globally, leading many foreign banks especially vulnerable to collapse, thus challenging governments globally to respond to the threatening destabilization of their economies. When the recent crisis struck, big central banks like the Fed in US, slashed their overnight interest rates to almost zero, in order to boost the economy, but the experiment failed to spark recovery. The new measure then to avoid a credit crunch obstacle was quantitative easing (QE). The fear regarding quantitative easing, especially in Germany stemmed from the hypothesis that if the European Central Bank (ECB) buys government bonds from Greece, Italy and Portugal, German taxpayers risk to pay the bill of bankruptcy. This would happen if one or more of these countries default on their debt. Germany, then, would have to step in to cover such loss, a fear that halted the ECB to begin its long awaited program of quantitative easing in 2015 (See also P. De Grauwe at "The Economist", as of Jan. 21 $\left.1^{\text {st }} 2015\right)$. Moreover, the drastic decline observed in loan growth during the intensification of the financial crisis in 2008 in Germany, raised serious concerns regarding an imminent or existing supply-side constraint in bank lending. Thus, politicians and entrepreneurs' associations in

\footnotetext{
${ }^{3}$ Bank for International Settlements (BIS), Long Series on total credit to the non-financial sectors, "http://www.bis.org/statistics/webinar2015.htm\#totcredit".
} 
Germany began to express their concerns that loan supply would, in fact, die down, and that the real side of the economy would be adversely affected by the malfunctioning of the German financial system, with EU and global as well repercussions (Deutsche Bundesbank, 2009; Busch, et al., 2010).

The data we apply in this work are quarterly figures on nominal credit to the private non-financial sector, at market value, in domestic currency and adjusted for breaks, from the BIS data base, for US, Japan and Germany, for the period of complete time series data from 1970(Q1) up to 2015(Q1). Transformation into real credit time series data is achieved through the St. Louis Fed open source data base ${ }^{4}$.

\section{A Short Credit Data History}

That credit is crucial for economic activity stems from the fact that households borrow to smooth consumption and purchase durable goods; firms require credit to finance investments, so that the private sector borrowing itself has significant implications influencing the monetary transmission mechanism and the countries' financial stability as well. Nevertheless, complete and appropriately compiled data capturing total credit to the private non-financial sector are scarce and, this research introduces an initial and substantial application of the new BIS database for three leading advanced economies; i.e., the US, Germany and Japan, in order to investigate global credit cycle repercussions, such as international credit cycles during financial crises globally.

The most recent BIS database for the total credit to the private non-financial sector guarantees significant international comparability and consistency across time, since uniform and quite advanced statistical criteria have been applied. This much of the international time series data comparability is satisfied by advanced, as said, statistical techniques adjustment for breaks whenever the borrower, lender or instrument coverage changed ${ }^{5}$. Since total credit captures lending from all sources, consolidation, i.e. netting out credit between institutional units of the same sector, lowers the measured level of total credit. Thus, the new BIS total credit time series are not consolidated, because for most purposes (e.g. debt sustainability), it is not relevant whether the source of credit is a bank or another corporate ${ }^{6}$.

As such then, the new BIS total credit series are fairly comparable across countries, particularly in the last $10-20$ years, where data are mainly based on financial accounts. These accounts reveal that over the last 60 years, credit has substantially outgrown GDP in almost all countries; whereas, banks may extend only around $30 \%$

\footnotetext{
${ }^{4}$ OECD (2010), "Main Economic Indicators - complete database",

"http://dx.doi.org/10.1787/data-00052-en", https://research.stlouisfed.org/fred2/series/, CPI data series.

${ }_{6}^{5}$ www.bis.org/statistics/credtopriv.htm.

${ }^{6}$ This BIS approach is also in line with the European Commission's "Scoreboard for the Surveillance of Macroeconomic Imbalances (EU, 2012).
} 
of total credit in the US, or close to $90 \%$ in heavily bank - based financial systems as Germany.

\section{Credit Cycles and Global Responses}

It is well known that traditional monetarists are consistent with the old-classic view that only "money-matters", so that even when bank credit tightening does occur during recessions, they see these as part of the endogenous financial system, rather than exogenous events that induce recessions. Brunner and Meltzer (1988) argue that banking crises are endogenous financial forces, which directly affect business cycles conditional on the monetary propagation mechanism. In contrast, the "New - Credit" viewers stress further the importance of credit restrictions, while accepting the fundamental inefficiencies of the monetary policy. The "New - Credit" view combines the "Old - Credit" view of the money to spend perspective, with the money to hold perspective of the money view. The "Old - Credit" view focused on decisions to create and spend money, on the expansion effects of bank lending, and emphasized the issue of the non-neutrality of credit money in the long-run (Trautwein, 2000). More so, due to the long theoretical debate between the advocates of the "Money View" (who emphasize the importance of demand effects for loan growth) and the proponents of the "Credit View" (who emphasize the role of supply effects), the majority of the running literature focuses on either the demand side or the supply side of the credit market (Trautwein, 2000) ${ }^{7}$. Kashyap and Stein (1994) leave no doubt while supporting Bernanke's (1983), and Bernanke's and James's (1991) seminal examination of the Great Depression in the US, that the conventional explanation for the depth and persistence of the Depression is one of the strongest pieces of evidence supporting the view that shifts in credit loan supply can be quite important globally.

Ever since the 80's of the previous century, G. Holtham (1988, p. 283) stressed evidently that "any US administration usually looks outward when it feels itself to be in economic difficulties". In turn, foreign policies are scrutinized from the US and the global repercussions are evaluated. That happened in 1971, 1978, and the mid 80's (Holtham, 1988). More so, the European Central Banks (then, at the European Monetary System, before the introduction of the euro currency) have agreed, through the BIS, on coordinated interest rate moves (Holtham, 1988). Still further, Holtham argues that a coordinated monetary easing (then; and "quantitative and credit easing", as of today) in Europe, Japan and the US, should lead to world interest rates and any incipient recessionary tendencies management in the world economy.

\footnotetext{
${ }^{7}$ It seems that the running empirical literature advances on this modeling shortcoming by either modeling both loan demand and supply in separate equations, as in the cointegration literature (e.g. Sørensen, et al, 2009), or by employing a VAR type approach that identifies structural shocks such as credit supply or credit demand shocks.
} 
Bearing in mind the late economic crisis and its global repercussions that still continue, we inevitably focus upon the global credit cycles, crunches and shock transmissions. This line of thinking involves bank lending and the perceived failure of banks to manage risk that leads to massive sell-off of their stocks, liquidity draining and, quite possibly, bank insolvency. This is the crucial time that Central Banks inject cash and credit into the global economy, taking thus a leading role towards the financial crisis resolution (Krugman, 2012; NYT). Still further, interbank lending can come to a dangerous halt, since banks remain fearful of dispensing capital to unstable counterparties; a threatening fact that freezes the trembling credit markets, thus making it too difficult for firms and individuals to use credit to finance purchases. The late years' decision of the US, Japan and European governments to take serious measures in financial institutions' recapitalization, seems to be a catalyst in convincing the global financial centers that it is continuously safe to lend. Thus seen, the issue of global credit cycles transmissions need be investigated still further, in order to enhance our current understanding of new possible economic causalities during the late serious crisis years.

More so, according to the IMF and the US Federal Reserve, "quantitative easing" (QE) undertaken since the global financial crisis of 2007 - 2008 has mitigated some of the economic problems since the crisis itself (Klyuev et al., 2009; Feldstein, 2011). A central bank enacts $Q E$ by purchasing a set quantity of bonds or other financial assets in financial markets from private institutions. The goal of this policy is to facilitate an expansion of private bank lending.

Since the advent of the recent global financial crisis of 2007 - 2008, "quantitative easing" was used by the US, Japan and the Eurozone, because their risk - free short term nominal interest rates were either at or close to zero. In the US, this interest rate is termed "the Federal Funds Rate". Before 2007, according to the Bank of Japan (BOJ), the central bank adopted QE on March, the $19^{\text {th }}, 2001$; where, the BOJ flooded commercial banks with excess liquidity to promote private lending, leaving them with large stocks of excess reserves and, therefore, little risk of a liquidity shortage (Bank of Japan, 2010). In late November 2008, the Fed started buying $\$ 600$ bn. in mortgage backed securities. By March 2009, it held \$1 trillion of bank debt, mortgage - backed securities, and treasure notes; this amount reached a peak of $\$ 2.1$ trillion in June 2010 (Federal Reserve, 2008)). Purchases were halted on October the $29^{\text {th }}, 2014$, after accumulating $\$ 4.5$ trillion in assets (Wolfers, 2014). Ever since 2003, the role of the interbank relationships and the credit channel in Germany is verified (Worms, 2003). Also, since 2008, there was s sequence of negative loan supply shocks of extraordinary magnitude in Germany; whereas, there were no significant monetary policy shocks, indicating that monetary policy was essentially neutral (Busch, et al., 2010).

On January the $22^{\text {nd }}, 2015$, the ECB announced an expanded asset purchase program, where $€ 60$ bn. per month of euro - area bonds from central governments, 
agencies and European institutions would be bought (BBC, 2015). On October the $31^{\text {st }}, 2014$, the Bank of Japan (BOJ) announced the expansion of its bond buying program, to buy $¥ 80$ trillion of bonds a year (Bank of Japan, 2014).

Introducing the Federal Reserve's response to the 2008 - 2009 financial crisis, Fed ex-Chairman B. Bernanke distinguished the new program, which he termed "credit easing" (CE), from the Japanese - type "quantitative easing" (QE). In his speech, he announced, "Our approach - which could be described as "credit easing" (CE) resembles "quantitative easing" $(\mathrm{QE})$ in one respect: It involves an expansion of the central bank's balance sheet. However, in a pure $(\mathrm{QE})$ regime, the focus of policy is the quantity of bank reserves, which are liabilities of the central bank; the composition of loans and securities on the asset side of the central bank's balance sheet is incidental. Indeed, although the BOJ policy approach during the $(\mathrm{QE})$ period was quite multifaceted, the overall stance of its policy was gauged primarily in terms of its target for bank reserves. In contrast, the Federal Reserve's "credit easing" approach focuses on the mix of loans and securities that it holds and on how this composition of assets affects credit conditions for households and businesses (Federal Reserve, 2009). In 2010, the Federal Reserve purchased $\$ 1.25$ trillion of mortgage - backed securities to support the sagging mortgage market. These purchases increased the monetary base in a way similar to a purchase of government securities (St. Louis Fed, 2010) ${ }^{8}$.

Essentially, the ECB and the BOJ focused their programs on direct lending to banks, reflecting the bank - centric structure of their financial systems, while the Federal Reserve expanded its respective monetary bases by purchasing bonds (B. W. Fawley \& C. J. Neely, 2013). It is indeed too difficult to learn how, in fact, credit easing as well as quantitative easing programs affect macroeconomic variables, such as output (see for example, Athanasenas, 2010; Helbling et. al., 2011; Eickmeier and Ng, $2011)^{9}$, employment, and/or inflation, since several economic factors such as investor expectations and production technologies also affect seriously these variables. Moreover, monetary policies, such as credit easing or quantitative easing,

\footnotetext{
${ }^{8}$ http://research.stlouisfed.org/publications/es/10/ES1014.pdf

9 Athanasenas (2010) investigated the macroeconomic fundamental issue of the causal relationship between credit and money income, for the case of the US postwar period 1957 2007, along the lines of the "credit view" theorists, applying a contemporary and new type of forecasting. Helbling et. al., (2011) estimated the importance of credit market shocks in driving global business cycles over the period of 1988 - 2009; Eickmeier and Ng (2011) studied how credit supply shocks in the US, the euro area and Japan are transmitted to other economies, for the period 1983 - 2009. Fadejeva et. al. (2017) examined the international effects of contractions in loan supply, loan demand and aggregate demand in the euro area and the USA. Now, we originally, incorporate the longest possible official Bank of International Settlements (BIS) credit time series data from 1970 - 2015; thus investigating in a classic and straightforward VAR approach, different but globally important financial crisis episodes (as of the 1970's vs. 2007 - 2009), such that this classic VAR analysis proves them to be the most significant credit supply episodes overall.
} 
are thought to affect macroeconomic variables with "long and variable lags", ever since M. Friedman's (1961) time (Neely, Fed. Res. Bank of St. Louis, 2014).

Finally, it is officially accepted (European Parliament, Directorate General for Internal Policies, 2012) that the first "stage" of the late financial crisis (2007 - 2009) was similar on both sides of the Atlantic and the response of the Fed and the ECB was also quite similar. Central Banks acted decisively in their response to the recent deepening crisis, by increasing dramatically their direct support to credit markets and, thus, increasing the size of their balance sheets. The Fed itself has been purchasing government bonds as well as the debt and mortgage - backed securities issued by the US government-sponsored enterprises. In fact, the Fed bypassed banks by giving credit directly to lenders and investors, or facilitated credit flows by making funding contingent on lending (IMF Staff Position Note, 2009). On the other side of the globe, the Bank of Japan (BOJ) focused largely on money creation via purchases of government bonds. In fact, the BOJ has scaled up the size of its outright purchases (of government bonds) from $¥ 1.2$ trillion per month in 2002 , up to $¥ 1.8$ trillion in March 2008 (IMF Staff Position Note, 2009).

Researchers, then, can investigate how (CE) and (QE) announcements affect asset prices, such as bond yields, exchange rates, equity and commodity prices, because asset prices respond quickly to new monetary information, such as (QE) and (CE) (Neely, 2014). Moreover, the significant role of the central banks on their effort to avoid future financial crises and the limits of macro-prudential instruments are quite recently analyzed (Wagner, 2010). Consequently, exploring the international credit cycles, in a globalized economy, becomes an important economic problem, with meaningful financial side-effects in specific countries that play a significant leading role in the global monetary system and its interconnections.

\section{The Theoretical Framework: Var Modelling Fundamentals}

The estimated augmented vector autoregressive model employed has the following form:

$$
\begin{aligned}
& z_{t}=a_{0}+a_{1} t+\sum_{i=1}^{p} \Phi_{i} z_{t-i}+\Psi_{w_{t}}+u_{t}=A^{\prime \prime} g_{t}+u_{t}, \\
& t=1,2, \ldots, n
\end{aligned}
$$

where, $z_{t}$ is an ( $\left.\mathrm{mx} 1\right)$ vector of jointly determined dependent variables and $\boldsymbol{w}_{\boldsymbol{t}}$ is an (q $x$ 1) vector of deterministic or exogenous variables (such as seasonal dummies or exogenously given variables such as foreign interest rates, or exchange rates).

The ( $\mathrm{m} \times 1)$ vector of disturbances satisfies the following assumptions:

1. $E\left(u_{t}\right)=0$

2. $E\left(u_{t} u_{t}^{\prime}\right)=\Sigma$ for all $\mathrm{t}$

3. $\boldsymbol{E}\left(\boldsymbol{u}_{\boldsymbol{t}} \boldsymbol{u}_{t^{\prime}{ }^{\prime}}\right)=\mathbf{0}$ for all $\mathrm{t} \neq t^{\prime \prime}$

Where $\boldsymbol{\Sigma}$ is an (m x m) positive definite matrix. 


\section{4. $E\left(u_{t} \mid w_{t}\right)=0$}

The augmented VAR(p) model (1) above, is stable; that is, all the roots of the determinantal equation $\left|I_{m}-\Phi_{1} \lambda-\Phi_{2} \lambda^{2}-\cdots-\Phi_{p} \lambda^{p}\right|=0$, fall outside the unit circle.

5. The $(\mathrm{m} \times 1)$ vector of disturbances have a multivariate normal distribution.

6. The observations $\boldsymbol{g}_{t}=\left(\mathbf{1}, \boldsymbol{t}_{,} z_{t-1}, z_{t-2}, \ldots, z_{t-p}, w_{t}\right)$, for $\mathrm{t}=1,2, \ldots, \mathrm{n}$ are not perfectly collinear.

Since the system of equations (1) above is in the form of a SURE model, with all the equations having the same set of regressors $g_{t}=\left(\mathbf{1}_{t}, \boldsymbol{t}_{t-1}, \mathbf{z}_{t-2}, \ldots, \mathbf{z}_{t-p}, \boldsymbol{w}_{t}\right)$, in common, it then follows that when $\boldsymbol{u}_{\boldsymbol{t}}$ are Gaussian, the ML estimators of the unknown coefficients can be computed by OLS regressions of $z_{\boldsymbol{t}}$ on $\boldsymbol{g}_{\boldsymbol{t}}$.

The order of the augmented VAR model (1), $\boldsymbol{p}$, can be selected either with the help of model selection criteria, such as the Akaike Information Criterion (AIC) or the Schwarz Bayesian Criterion (SBC), or by means of a sequence of log-likelihood ratio tests.

The log-likelihood ratio statistics for testing the deletion of a set of variables $\boldsymbol{w}_{\boldsymbol{t}}$, from the $\operatorname{VAR}(\mathrm{p})$ model (1) above, such that,

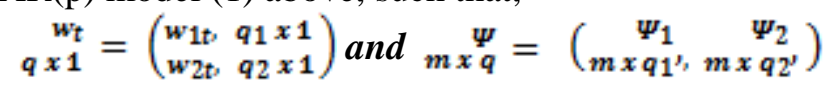

Where $q=q_{1}+q_{2}$. We test, then, the null hypothesis that:

$$
H_{0}: \Psi_{1}=0 \text {, against } H_{1}: \Psi_{1} \neq 0 \text {. }
$$

Testing for block Granger non-causality, we go through the following fundamentals. We let $z_{t}=\left(z_{1 t}^{\prime}, z_{2 t}^{\prime}\right)^{\prime}$, where $z_{1 t}$ and $z_{2 t}$ are $m_{1} x 1$ and $m_{2} x 1_{s}\left(m_{1}+m_{2}=m\right)$ variables, and partition the system of equations (1) into the next two sub-systems:

$$
\begin{aligned}
& Z_{1}=Y_{1} A_{11}+Y_{2} A_{12}+W A_{13}+U_{1} \\
& Z_{2}=Y_{1} A_{21}+Y_{2} A_{22}+W A_{23}+U_{2}
\end{aligned}
$$

where $\boldsymbol{Z}_{1}$ and $\boldsymbol{Z}_{2}$ are $\left(n x m_{1}\right)$ and $\left(n x m_{2}\right)$ matrices of observations on $z_{1 t}$ and $z_{2 t}$ respectively; $\boldsymbol{Y}_{1}$ and $\boldsymbol{Y}_{2}$ are $\left(n x p m_{1}\right)$ and $\left(n x p m_{2}\right)$ matrices of observations on the $p$ lagged values of $z_{1, t-l}$ and $z_{2, t-l}$ for $t=1,2, \ldots, n, l=1,2, \ldots, p$, respectively. The hypothesis that " $z_{2 t}$ do not Granger cause $z_{1 t}$ " is defined by the $m_{1} m_{2} p$ restrictions $A_{12}=0$.

The impulse response function measures the time span of the effect of shocks on the future states of a dynamical system. The orthogonalized impulse response (IR) function is advanced by C. Sims $(1980,1981)$. The generalized impulse response function is proposed by Koop et al. (1996) and Pesaran and Shin (1997). 
Given the (m x m) matrices $\boldsymbol{A}_{\boldsymbol{i}}$, both impulse response functions work with these coefficients, in the infinite moving average representation of:

$$
z_{t}=\sum_{j=0}^{\infty} A_{j} u_{t-j}+\sum_{j=0}^{\infty} B_{j} w_{t-j}
$$

where, the matrices, $\boldsymbol{A}_{\boldsymbol{j}}$, are computed using the recursive relations

$$
A_{j}=\Phi_{1} A_{j-1}+\Phi_{2} A_{j-2}+\ldots+\Phi_{p} A_{j-p}, \quad j=1,2, \ldots
$$

with $\boldsymbol{A}_{\mathbf{0}}=\boldsymbol{I}_{\boldsymbol{m}}$, and $\boldsymbol{A}_{\boldsymbol{j}}=\mathbf{0}$, for $\mathrm{j}<0$, and $\boldsymbol{B}_{\boldsymbol{j}}=\boldsymbol{A}_{j} \boldsymbol{\Psi}$, for j $=1,2, \ldots$

C. Sims' approach employs the Cholesky decomposition of $\Sigma$; that is, the covariance matrix of the shocks, $u_{t}: \Sigma=T \boldsymbol{T}^{\prime}$, where $\boldsymbol{T}$ is a lower triangular matrix. C. Sims then rewrites the moving average representation (2) as follows:

where:

$$
z_{t}=\sum_{j=0}^{\infty}\left(A_{j} T\right)\left(T^{-1} u_{t-j}\right)+\sum_{j=0}^{\infty} B_{j} w_{t-j}=\sum_{j=0}^{\infty} A_{j}^{*} \varepsilon_{t-j}+\sum_{j=0}^{\infty} B_{j} w_{t-j}
$$

$$
A_{j}^{*}=A_{j} T_{j} \text { and } \varepsilon_{t}=T^{-1} u_{t},
$$

and $E\left(\varepsilon_{t} \varepsilon_{t}^{\prime}\right)=T^{-1} E\left(u_{t} u_{t}^{\prime}\right) T^{\prime-1}=T^{-1} \Sigma T^{\prime-1}=I_{m}$, where, the shocks $\varepsilon_{t}=\left(\varepsilon_{1 t}, \varepsilon_{2 t, \ldots,} \varepsilon_{m t}\right)^{\prime}$ are orthogonal to each other. The orthogonalized impulse responses are not unique and, in general, depend on the particular ordering of the variables in the VAR. The orthogonalized responses are invariant to the ordering of the variables only if $\boldsymbol{\Sigma}$ is diagonal.

The idea behind the generalized IR function is to circumvent the problem of the dependence of the orthogonalized impulse responses on the ordering of the variables in the VAR (Koop et al., 1996), such that the generalized impulse responses are "history" invariant to this variables' ordering. The generalized IR, then, for a system - wide shock, $\boldsymbol{u}_{t}^{0}$, is defined by:

$$
G I_{z}\left(N, u_{t}^{0}, \Omega_{t-1}^{0}\right)=E\left(z_{t+N} \mid u_{t}=u_{t}^{0}, \Omega_{t-1}^{0}\right)-E\left(u_{t+N} \mid \Omega_{t-1}^{0}\right)
$$

where, $E\left(. \|_{.}\right)$is the conditional mathematical expectation taken with respect to the VAR model (1), and $\Omega_{t-1}^{0}$ is a particular "historical" realization of the process at time (t-1). With a VAR model having the infinite moving-average representation (2) above, we have:

$$
G I_{z}\left(N, u_{t}^{0} \Omega_{t-1}^{0}\right)=A_{N} u_{t,}^{0}
$$

which is independent of the "history" of the process; that is, a property specific to linear systems that does not hold in the case of non-linear dynamic models. Practically, the choice of the vector of shocks, $u_{t}^{0}$, is arbitrary. What is also interesting to note is that the two impulse responses coincide only for the first variable in the VAR, or when $\boldsymbol{\Sigma}$ is diagonal (Pesaran and Shin, 1997).

\section{Results}

Our results consider first the order of the trivariate VAR model in the real credit growths of USA, Japan and Germany. Our data cover the period of 1970(Q1) up to 
$2015(\mathrm{Q} 1)^{10}$. Since the aim is to select an "optimal" order for the VAR, it is important that we select an order high enough to be reasonably confident that the "optimal" lag order will be included. Therefore, we start by using (8) as the maximum order for the VAR, given the economic intuition behind credit movement expectations. All the nine VAR(p), $\mathrm{p}=0,1,2, \ldots, 8$, models are estimated over the sample period 1972(Q1) up to 2014(Q4) and, as expected, the maximum values of the log-likelihood function (column headed LL) increase with (p). However, the Akaike (AIC) and the Schwarz (SBC) criteria select the order (7) and (4), respectively (Table 1).

Table 1. Test Statistics and Choice Criteria for Selecting the Order of the VAR Model

Based on 172 observations from 1972Q1 to 2014Q4. Order of VAR $=8$

List of variables included in the unrestricted VAR: DLCUSA, DLCJAP, DLCGER

List of deterministic and/or exogenous variables: CONST

\begin{tabular}{cccccc}
\hline Order & LL & AIC & SBC & LR test & Adjusted LR test \\
8 & 1784.4 & 1709.4 & 1591.3 & ---- & ---- \\
7 & 1776.9 & 1710.9 & 1607.0 & CHSQ( 9)= 14.9885[.091] & $12.8100[.171]$ \\
6 & 1762.1 & 1705.1 & 1615.4 & CHSQ( 18)= 44.6354[.000] & $38.1477[.004]$ \\
5 & 1745.8 & 1697.8 & 1622.2 & CHSQ( 27)= 77.1722[.000] & $65.9553[.000]$ \\
4 & 1737.5 & 1698.5 & 1637.1 & CHSQ (36)= 93.8420[.000] & $80.2022[.000]$ \\
3 & 1684.7 & 1654.7 & 1607.4 & CHSQ( 45)=199.4444[.000] & $170.4554[.000]$ \\
2 & 1643.5 & 1622.5 & 1589.5 & CHSQ( 54)=281.6764[.000] & $240.7351[.000]$ \\
1 & 1606.6 & 1594.6 & 1575.7 & CHSQ( 63)=355.5105[.000] & $303.8375[.000]$ \\
0 & 1546.7 & 1543.7 & 1538.9 & CHSQ( 72)=475.4234[.000] & $406.3212[.000]$ \\
\hline
\end{tabular}

$\mathrm{AIC}=$ Akaike Information Criterion $\mathrm{SBC}=$ Schwarz Bayesian Criterion

The log-likelihood ratio statistics, whether adjusted for small samples or not, do not reject a VAR of order (7). In the light of this outcome, we choose the VAR(7) model, as the most appropriate, given also that the SBC criterion does indeed select a usually lower order VAR, that is (4), as compared with the AIC. Having chosen the "optimal" VAR order, it is quite prudent to examine the residuals of all individual equations, for serial correlation. There is no evidence of residual serial correlation in the case of the US and Germany's credit equations, but there is a statistically significant evidence of residual serial correlation in the case of Japan's credit growth equation. There is also important evidence of departures from

\footnotetext{
${ }^{10}$ Considering univariate unit root tests for the relevant variables, since the credit growth is not trended, the relevant ADF statistics are estimated for the three country cases, i.e.: DLCUSA, DLCJAP and DLCGER. The model selection criteria (provided as requested) suggest that the process of US credit growth can be approximated by an AR(7) process, with the AIC selecting an AR(7) process and the SBC selecting an AR(6) process, respectively. Accordingly, the corresponding values for the German credit growth is for AIC an AR(7) process and for SBC an AR(3) process; whereas, for the Japanese credit growth and the AIC, it is an $A R(7)$ process and for $S B C$ an $A R(7)$ process also.
} 
normality and functional form specification in the case of credit growth equation for Japan $^{11}$.

A closer examination of the residuals of these equations suggest considerable and statistically significant volatility during the early 1970's (1973), most probably due to the abandonment of the Bretton-Woods system and the quadrupling increase in oil prices, as well as during the 2008 year of the recent and still expanding financial crisis of 2007-2008. Therefore, these crucial possibilities can be handled by introducing a dummy variable for the oil shock in the VAR model for 1973 and, separately, for the late financial crisis in the VAR model for 2008, as well.

\section{The 1973 oil shock experiment in credit equations ${ }^{12}$}

Testing the significance of an oil shock dummy variable (Table 2), the log-likelihood ratio statistic for testing the deletion of the oil shock dummy from all three credit growth equations is 8,30 which is statistically significant at the 4,0 per cent level.

Table 2. LR Test of Deletion of Deterministic/Exogenous Variables in the VAR

Based on 173 observations from 1971Q4 to 2014Q4. Order of VAR = 7

List of variables included in the unrestricted VAR: DLCUSA, DLCJAP, DLCGER, List of deterministic and/or exogenous variables: CONST, D73

Maximized value of log-likelihood $=1788.8$

List of variables included in the restricted VAR: DLCUSA, DLCJAP, DLCGER

List of deterministic and/or exogenous variables: CONST

Maximized value of $\log$-likelihood $=1784.7$

LR test of restrictions, CHSQ( 3)=8.3008[.040]

The inclusion of the dummy has not eliminated the problem of serial correlation, functional form or normality for the Japanese economy, thus revealing other significant factors (such as non-linear effects) that should be taken into account in different econometric modelling system structures ${ }^{13}$.

The same picture holds with a higher order for the VAR(12) model for serial correlation and normality, although this procedure is not recommended by the model selection criteria or the likelihood ratio statistics, for the Japanese credit growth equation.

Now, one highly important issue in our analysis of the international credit cycle is the extent to which credit growth shocks are transmitted from one country to another, for these three leading advanced economies. This crucial issue is examined

\footnotetext{
${ }^{11}$ All regression results are readily available upon request and are not reported here due only to space limitations.

${ }_{12}$ Applied as a 1973 dummy variable.

${ }^{13}$ The previous footnote (9) applies also here, as well.
} 
by Granger non-causality tests, as they are applied to the specific trivariate VAR in the US, Japanese, and German credit growth equations. The results of these tests are shown in tables (3), (4), and (5).

Table 3. LR Test of Block Granger Non-Causality in the VAR

Based on 173 observations from 1971Q4 to 2014Q4. Order of VAR $=7$

List of variables included in the unrestricted VAR: DLCUSA, DLCJAP, DLCGER

List of deterministic and/or exogenous variables: CONST, D73

Maximized value of log-likelihood $=1788.8$

List of variable(s) assumed to be "non-causal" under the null hypothesis:

DLCJAP DLCGER

Maximized value of log-likelihood $=1771.3$

LR test of block non-causality, CHSQ( 14)=35.1536[.001]

The above statistic is for testing the null hypothesis that the coefficients of the lagged values of: DLCJAP, DLCGER, in the block of equations explaining the variable(s): DLCUSA are zero. The maximum order of the $\operatorname{lag}(\mathrm{s})$ is 7 .

Table 4. LR Test of Block Granger Non-Causality in the VAR

Based on 173 observations from 1971Q4 to 2014Q4. Order of VAR = 7

List of variables included in the unrestricted VAR: DLCUSA, DLCJAP, DLCGER

List of deterministic and/or exogenous variables: CONST, D73

Maximized value of log-likelihood $=1788.8$

List of variable(s) assumed to be "non-causal" under the null hypothesis: DLCUSA,

DLCGER

Maximized value of log-likelihood $=1773.2$

LR test of block non-causality, CHSQ( 14)= 31.3371[.005]

The above statistic is for testing the null hypothesis that the coefficients of the lagged values of: DLCUSA, DLCGER, in the block of equations explaining the variable(s): DLCJAP are zero. The maximum order of the $\operatorname{lag}(\mathrm{s})$ is 7 .

Table 5. LR Test of Block Granger Non-Causality in the VAR

Based on 173 observations from 1971Q4 to 2014Q4. Order of VAR = 7

List of variables included in the unrestricted VAR: DLCUSA, DLCJAP, DLCGER

List of deterministic and/or exogenous variables: CONST, D73

Maximized value of log-likelihood $=1788.8$

List of variable(s) assumed to be "non-causal" under the null hypothesis: DLCUSA,

DLCJAP

Maximized value of log-likelihood $=1763.6$

LR test of block non-causality, CHSQ( 14) $=50.5356[.000]$

The above statistic is for testing the null hypothesis that the coefficients of the lagged values of: DLCUSA, DLCJAP, in the block of equations explaining the variable(s): DLCGER are zero. The maximum order of the $\operatorname{lag}(\mathrm{s})$ is 7 .

The log-likelihood ratio statistic for this test and the US credit growth equation is equal to $35.1536(0.001)$, which is asymptotically distributed as a $\mathrm{X}^{2}$ variable with 
14 degrees of freedom and, it is clearly statistically significant. Similarly, carrying out the same exercise for the other two credit growth equations, we obtain the LR statistic of $31.3371(0.005)$ when testing for the non-causality of the US and Germany's credit growth in the Japanese credit growth equation and, the corresponding LR statistic of 50.5356 (0.000) for testing the non-causality of the US and Japanese credit growth in Germany's credit equation. The figures in brackets refer, of course, to rejection probabilities. Therefore, and more crucially, if there are any significant transmissions of credit shocks among these three lading economies, during the 70's, it seems that these transmissions are going from one leading economy to the other two.

Another crucial aspect of the international transmission of credit shocks is definitely the extent to which credit shocks in different credit equations (and economies) are contemporaneously correlated. In this important test, we examine the statistical behavior of the contemporaneous covariance between the shocks in the credit equations of these three countries. Computing, thus, the appropriate log-likelihood ratio statistic proves that the null hypothesis that the shocks in different credit equations are contemporaneously un-correlated can be rejected at the 95 per cent critical value of the $X^{2}$ distribution (with 3 degrees of freedom, being 7.81 and, the LR statistic estimated value of 346.8912$)^{14,15}$.

Additionally, however, the estimates of the corresponding covariances between the credit shocks in all credit equations of countries $i$ and $j, \sigma_{i j}$, still question the above finding (table 6).

Table 6. Estimated System Covariance Matrix of Errors

$\begin{array}{lccc} & \text { DLCUSA } & \text { DLCJAP } & \text { DLCGER } \\ \text { DLCUSA } & .5165 \mathrm{E}-4 & .4948 \mathrm{E}-5 & .1073 \mathrm{E}-4 \\ \text { DLCJAP } & .4948 \mathrm{E}-5 & .1107 \mathrm{E}-3 & .2700 \mathrm{E}-5 \\ \text { DLCGER } & .1073 \mathrm{E}-4 & .2700 \mathrm{E}-5 & .5870 \mathrm{E}-4\end{array}$

Our next step here is to compute multivariate ahead forecasts of credit growths. Thus, we apply the VAR(7) model of credit growths of the US, Japan and Germany, over the period 1971(Q4) to 2014(Q4). These forecasts are reproduced in tables ((7), (8), and, (9)).

\footnotetext{
${ }^{14}$ Here, we test the hypothesis that $\left(\boldsymbol{H}_{0}: \sigma_{12}=\sigma_{13}=\sigma_{23}=0\right)_{x}$ against the alternative that $\left(H_{1}: \sigma_{12} \neq 0, \sigma_{13} \neq 0, \sigma_{23} \neq 0\right)$, where $\sigma_{i j}$ stands for the contemporaneous covariance between the shocks in the credit equations of countries $\boldsymbol{i}$ and $\boldsymbol{j}$, respectively. In this analysis, we test the above hypothesis by computing the log-likelihood ratio statistic $\boldsymbol{L R}\left(\boldsymbol{H}_{0} \mid \boldsymbol{H}_{1}\right)=\mathbf{2}\left(\boldsymbol{L} \boldsymbol{L}_{U}-\boldsymbol{L} \boldsymbol{L}_{R}\right)$, where $\boldsymbol{L} \boldsymbol{L}_{U}$ and $\mathbf{L} \boldsymbol{L}_{R}$ are the maximized values of the loglikelihood function under $\boldsymbol{H}_{1}$ (the unrestricted model) and under $\boldsymbol{H}_{0}$ (the restricted model), respectively.

${ }^{15}$ All results are readily available upon request, as stated for the previous cases before.
} 
Table 7. Multivariate Dynamic Forecasts for the Level of DLCUSA

Based on 173 observations from 1971Q4 to 2014Q4. Order of VAR = 7

List of variables included in the unrestricted VAR: DLCUSA, DLCJAP, DLCGER

List of deterministic and/or exogenous variables: CONST, D73

$\begin{array}{lccl}\text { Observation } & \text { Actual } & \text { Prediction } & \text { Error } \\ 2015 Q 1 & .0084390 & .0018354 & .0066036\end{array}$

Summary Statistics for Residuals and Forecast Errors

\begin{tabular}{lcc}
\hline & Estimation Period & Forecast Period \\
& 1971Q4 to 2014Q4 & 2015Q1 to 2015Q1 \\
\hline Mean & -.0000 & .0066036 \\
Mean Absolute & .0051940 & .0066036 \\
Mean Sum Squares & $.4478 \mathrm{E}-4$ & $.4361 \mathrm{E}-4$ \\
Root Mean Sum Squares & .0066921 & .0066036 \\
\hline
\end{tabular}

Table 8. Multivariate Dynamic Forecasts for the Level of DLCJAP

Based on 173 observations from 1971Q4 to 2014Q4. Order of VAR =7

List of variables included in the unrestricted VAR: DLCUSA, DLCJAP, DLCGER

List of deterministic and/or exogenous variables: CONST, D73
Observation
Actual
Prediction
Error
2015Q1
$.6434 \mathrm{E}-3$
$.4316 \mathrm{E}-3$
$.2118 \mathrm{E}-3$

Summary Statistics for Residuals and Forecast Errors

\begin{tabular}{lcc}
\hline & $\begin{array}{c}\text { Estimation Period } \\
\text { 1971Q4 to 2014Q4 }\end{array}$ & $\begin{array}{c}\text { Forecast Period } \\
\text { 2015Q1 to 2015Q1 }\end{array}$ \\
\hline Mean & -.0000 & $.2118 \mathrm{E}-3$ \\
Mean Absolute & .0068105 & $.2118 \mathrm{E}-3$ \\
Mean Sum Squares & $.9602 \mathrm{E}-4$ & $.4484 \mathrm{E}-7$ \\
Root Mean Sum Squares & .0097992 & $.2118 \mathrm{E}-3$ \\
\hline
\end{tabular}

Table 9. Multivariate Dynamic Forecasts for the Level of DLCGER

Based on 173 observations from 1971Q4 to 2014Q4. Order of VAR = 7

List of variables included in the unrestricted VAR: DLCUSA, DLCJAP, DLCGER

List of deterministic and/or exogenous variables: CONST, D73
Observation
Actual
Prediction
Error
2015Q1
.020802
$-.0038929$
.024695

Summary Statistics for Residuals and Forecast Errors

\begin{tabular}{lcc}
\hline & $\begin{array}{c}\text { Estimation Period } \\
\text { 1971Q4 to 2014Q4 }\end{array}$ & $\begin{array}{c}\text { Forecast Period } \\
\text { 2015Q1 to 2015Q1 }\end{array}$ \\
\hline Mean & -.0000 & .024695 \\
Mean Absolute & .0057735 & .024695 \\
Mean Sum Squares & $.5089 \mathrm{E}-4$ & $.6098 \mathrm{E}-3$ \\
Root Mean Sum Squares & .0071340 & .024695 \\
\hline
\end{tabular}

As can be seen from the summary statistics, the size of the forecast errors and the insample residuals are satisfactorily similar, especially for the US economy and, much less for the Japanese and German economies, as can be verified by closely inspecting the root mean sum of squares. Of course, it is crucially important to stress 
that the US credit growth, as well that of Japan and Germany, in 2015(Q1) were all positive and our forecast considers here only one quarter ahead, with the German productivity value negative. More detailed forecast performance would require the examination of the VAR modeling prediction ability on further ahead periods and turning points credit movements.

Finally, we comment upon the results of estimating impulse responses for the effect of a unit shock (equal to one standard error) to the US credit growth equation on the growth of credit in Japan and Germany, within the trivariate VAR model ${ }^{16}$.

As we can see, the effect of a unit shock to the US credit growth has only a small impact on the credit growths of Japan and Germany and this effect dies out relatively quickly with the forecast horizon. Figure (1) also verifies this outcome.

\section{Figure 1:}

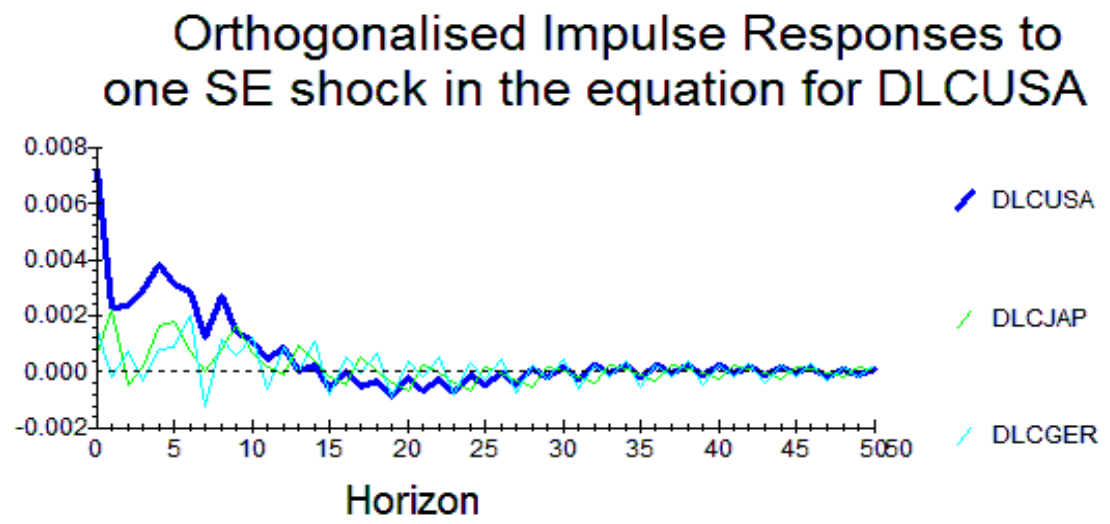

Considering now the generalized impulse responses of the effect of a unit shock to DLCUSA, since DLCUSA is the first variable in the VAR, the orthogonalized and generalized impulse responses are identical. This is not, however, the case, if we choose to shock Japan's or Germany's credit growth equation. Figures ( $3 \& 4)$ for Japan and figures $(5 \& 6)$ for Germany show the small impacts, respectively.

\footnotetext{
${ }^{16}$ The results of the orthogonalized (and the generalized) impulse responses to one standard error in the equation for the US credit growth (DLCUSA), using an unrestricted vector autoregressive model, as well as for the Japan and the German credit growth equations, (DLCJAP) and (DLCGER) accordingly, are all readily available upon request. They are not reported here, again, due to space limitations.
} 
Figure 2:

Generalised Impulse Responses to one SE shock in the equation for DLCUSA

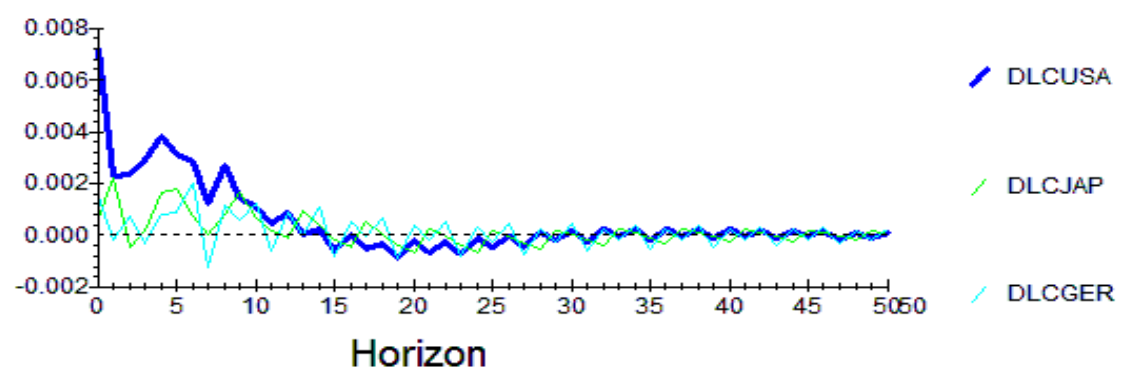

Figure 3:

Orthogonalised Impulse Responses to one SE shock in the equation for DLCJAP

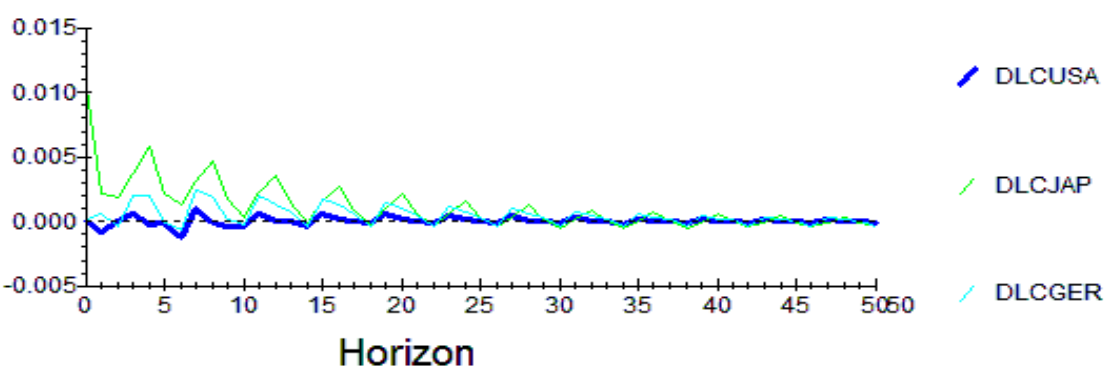

Figure 4:

Generalised Impulse Responses to one SE shock in the equation for DLCJAP

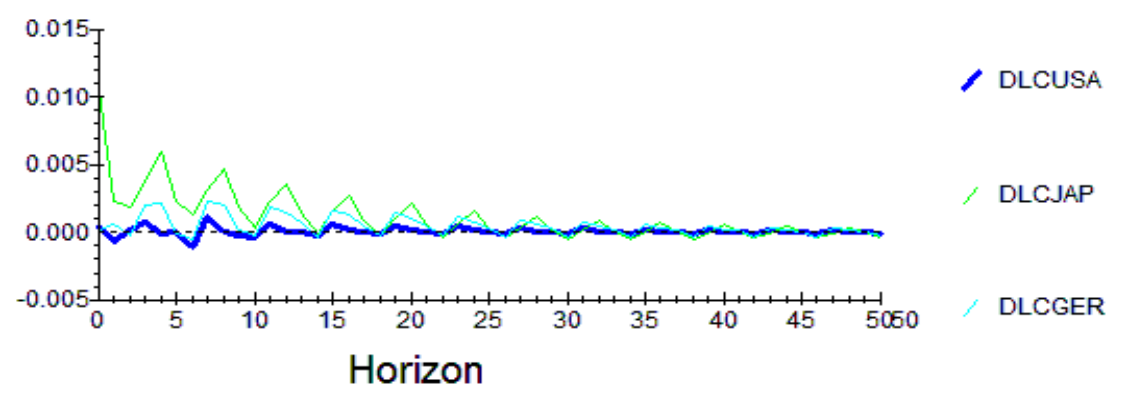


Figure 5:

Orthogonalised Impulse Responses to one SE shock in the equation for DLCGER

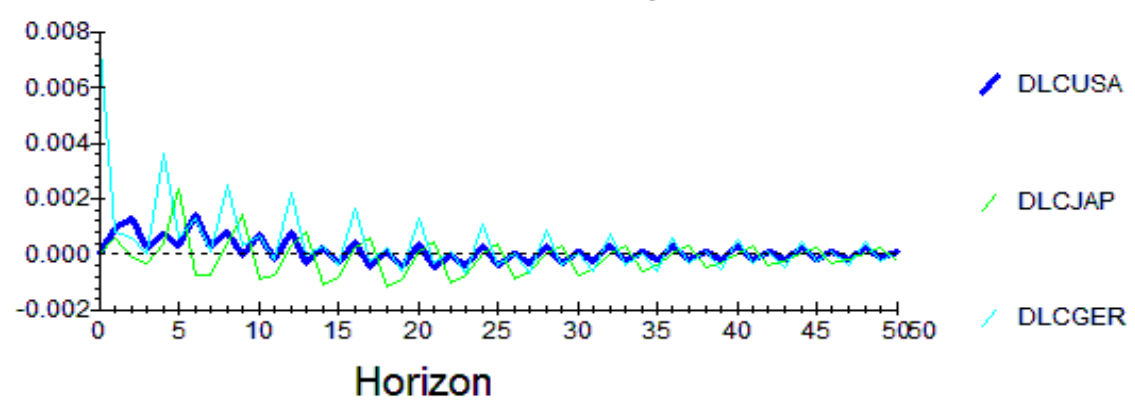

Figure 6:

Generalised Impulse Responses to one SE shock in the equation for DLCGER

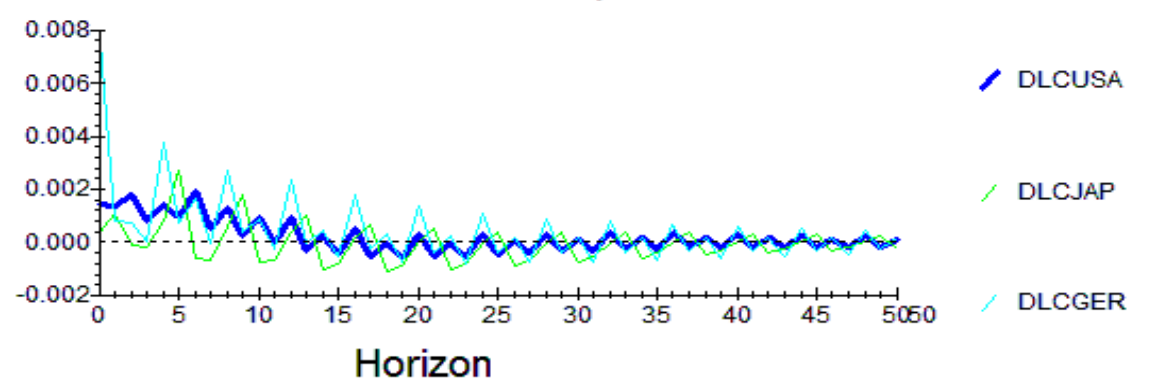

\section{The 2008 financial crisis experiment in credit equations ${ }^{17}$}

Given our previous statements, after examining the residuals of the credit growth equations in great detail, we noticed a statistically significant volatility during the 2008 year of the recent financial crisis of 2007 - 2008; that is, a fact that lies on the center of our credit transmission analysis, among three advanced and capitalism leading economies. Consequently, we further introduce a dummy variable for the credit shock in the VAR model for 2008 and, proceed with the following results.

Testing the significance of the credit shock dummy variable (table 10), the loglikelihood ratio statistic for testing the deletion of the credit shock dummy from all three credit growth equations, is statistically significant at the 3.2 per cent level.

\footnotetext{
${ }^{17}$ Applied as a 2008 dummy variable.
} 
Table 10. LR Test of Deletion of Deterministic/Exogenous Variables in the VAR

Based on 173 observations from 1971Q4 to 2014Q4. Order of VAR = 7

List of variables included in the unrestricted VAR: DLCUSA, DLCJAP, DLCGER

List of deterministic and/or exogenous variables: CONST, D08

Maximized value of log-likelihood $=1789.1$

List of variables included in the restricted VAR: DLCUSA, DLCJAP, DLCGER

List of deterministic and/or exogenous variables: CONST

Maximized value of log-likelihood $=1784.7$

LR test of restrictions, CHSQ( 3)= 8.8074[.032]

This dummy variable is significant in the US credit growth equation, but not in the case of the Japanese and the German equations ${ }^{18}$. Once again, the inclusion of this new dummy variable has not eliminated the problem of serial correlation, functional form or normality, for the Japanese economy, thus enhancing the fact that other significant factors, such as non-linear effects should be taken into account in a different econometric modeling structure; definitely, though, after exploiting all possible linearities involved in this first analysis here, that is our important fist linear step.

Thus, incorporating a higher order for the VAR(12) model, we still face an overall relative improvement for the US and German economies' modeling statistics, with certain normality problems and a functional form improvement only (without improvement for serial correlation and normality) for the Japanese credit growth equation. These facts reveal not only non-linear possible effects, but also hints for different econometric modeling system structures, that could possibly capture still unknown global credit transmission impulses.

Accordingly, then, we re-estimate the extent to which credit growth shocks are transmitted from one country to another, for these three leading economies in particular and, with the new 2008 dummy included. The Granger non-causality tests are shown in tables (11) for the US, (12) for the Japanese and, (13) for the German economy. The log-likelihood ratio statistic for this test and the US credit growth equation is equal to $36.6873(0.001)$, that is asymptotically distributed as a $\mathrm{X}^{2}$ variate with 14 degrees of freedom and, it is clearly statistically significant. We next obtain the LR statistic of 32.0209(0.004) when testing again for the non-causality of the US and Germany's credit growth in the Japanese credit equation, and the corresponding LR statistic of 48.9030(0.000) in the Germany's credit equation. Once again, as it was the case during the 70's before, it seems that these credit shock transmissions among these three leading economies are going from one country to the other two. Thus, we face statistical evidence that global financial crises, as well as credit supply shocks, in economies that lead capitalism globally, affect each other seriously.

\footnotetext{
${ }^{18}$ The same previous footnotes on results availability apply here too.
} 
Table 11. LR Test of Block Granger Non-Causality in the VAR

\begin{tabular}{l} 
Based on 173 observations from 1971Q4 to 2014Q4. Order of VAR = 7 \\
List of variables included in the unrestricted VAR: DLCUSA, DLCJAP, DLCGER \\
List of deterministic and/or exogenous variables: CONST, D08 \\
Maximized value of log-likelihood = 1789.1 \\
\hline List of variable(s) assumed to be "non-causal" under the null hypothesis: \\
DLCJAP DLCGER \\
Maximized value of log-likelihood $=1770.7$ \\
LR test of block non-causality, CHSQ( 14$)=36.6873[.001]$ \\
The above statistic is for testing the null hypothesis that the coefficients \\
of the lagged values of: DLCJAP, DLCGER, in the block of equations explaining the \\
variable(s): DLCUSA are zero. The maximum order of the lag(s) is 7.
\end{tabular}

Table 12. LR Test of Block Granger Non-Causality in the VAR

\begin{tabular}{l} 
Based on 173 observations from 1971Q4 to 2014Q4. Order of VAR = 7 \\
List of variables included in the unrestricted VAR: DLCUSA, DLCJAP, DLCGER \\
List of deterministic and/or exogenous variables: CONST, D08 \\
Maximized value of log-likelihood = 1789.1 \\
\hline List of variable(s) assumed to be "non-causal" under the null hypothesis: \\
DLCUSA DLCGER \\
Maximized value of log-likelihood $=1773.1$ \\
LR test of block non-causality, CHSQ $(14)=32.0209[.004]$ \\
The above statistic is for testing the null hypothesis that the coefficients \\
of the lagged values of: DLCUSA, DLCGER, in the block of equations explaining the \\
variable(s): DLCJAP are zero. The maximum order of the lag(s) is 7.
\end{tabular}

Table 13. LR Test of Block Granger Non-Causality in the VAR
Based on 173 observations from 1971Q4 to 2014Q4. Order of VAR = 7
List of variables included in the unrestricted VAR: DLCUSA, DLCJAP, DLCGER
List of deterministic and/or exogenous variables: CONST, D08
Maximized value of log-likelihood $=1789.1$
List of variable(s) assumed to be "non-causal" under the null hypothesis:
DLCUSA DLCJAP
Maximized value of log-likelihood $=1764.6$
LR test of block non-causality, CHSQ( 14)= 48.9030[.000]
The above statistic is for testing the null hypothesis that the coefficients of the lagged values of: DLCUSA, DLCJAP, in the block of equations explaining the variable(s): DLCGER are zero. The maximum order of the $\operatorname{lag}(\mathrm{s})$ is 7.

Next, we check for the contemporaneous correlation, among different credit equations, of credit shocks. Again then, we estimate the appropriate log-likelihood ratio statistic, that proves that the shocks in different country credit equations are contemporaneously un-correlated can be rejected at the 95 per cent critical value of 
the $\mathrm{X}^{2}$ distribution with a value of $344.6822^{19}$. Crucially, though, the estimates of the corresponding covariances between the country credit shocks, question the above finding (table 14$)^{20}$.

Table 14. Estimated System Covariance Matrix of Errors

\begin{tabular}{llll}
\hline & DLCUSA & DLCJAP & DLCGER \\
DLCUSA & $.5060 \mathrm{E}-4$ & $.7704 \mathrm{E}-5$ & $.1172 \mathrm{E}-4$ \\
DLCJAP & $.7704 \mathrm{E}-5$ & $.1131 \mathrm{E}-3$ & $.4000 \mathrm{E}-5$ \\
DLCGER & $.1172 \mathrm{E}-4$ & $.4000 \mathrm{E}-5$ & $.5934 \mathrm{E}-4$ \\
\hline
\end{tabular}

Next estimate is the computation of the multivariate ahead forecasts of credit growths. Tables (15) for the US, (16) for the Japanese and, (17) for the German economy, show the relative results. The summary statistics show that again the size of the forecast errors and the in-sample residuals are satisfactorily similar especially for the US economy and less for the Japanese and the German economies, that much being verified by inspecting the root mean sum of squares.

Table 15. Multivariate Dynamic Forecasts for the Level of DLCUSA

Based on 173 observations from 1971Q4 to 2014Q4. Order of VAR $=7$

List of variables included in the unrestricted VAR: DLCUSA, DLCJAP, DLCGER

List of deterministic and/or exogenous variables: CONST, D08

$\begin{array}{cccc}\text { Observation } & \text { Actual } & \text { Prediction } & \text { Error } \\ 2015 Q 1 & .0084390 & .0019357 & .0065034\end{array}$

Summary Statistics for Residuals and Forecast Errors

\begin{tabular}{lcc}
\hline & Estimation Period & Forecast Period \\
1971Q4 to 2014Q4 & 2015Q1 to 2015Q1 \\
\hline Mean & .0000 & .0065034 \\
Mean Absolute & .0051889 & .0065034 \\
Mean Sum Squares & $.4387 \mathrm{E}-4$ & $.4229 \mathrm{E}-4$ \\
Root Mean Sum Squares & .0066237 & .0065034
\end{tabular}

Table 16. Multivariate Dynamic Forecasts for the Level of DLCJAP

Based on 173 observations from 1971Q4 to 2014Q4. Order of VAR = 7

List of variables included in the unrestricted VAR: DLCUSA, DLCJAP, DLCGER

List of deterministic and/or exogenous variables: CONST, D08

$\begin{array}{lccc}\text { Observation } & \text { Actual } & \text { Prediction } & \text { Error } \\ \text { 2015Q1 } & .6434 \mathrm{E}-3 & .7223 \mathrm{E}-3 & -.7891 \mathrm{E}-4\end{array}$

Summary Statistics for Residuals and Forecast Errors

$\begin{array}{cc}\text { Estimation Period } & \text { Forecast Period } \\ \text { 1971Q4 to 2014Q4 } & \text { 2015Q1 to 2015Q1 }\end{array}$

\footnotetext{
${ }^{19}$ All relevant results are available upon request.

${ }^{20}$ The estimates of $\sigma_{i j}$ show that the summation of $\hat{\sigma}_{12}, \hat{\sigma}_{13}, \hat{\sigma}_{2 a}$, are about $1 / 10$ of the estimated error variances given by the diagonal elements of the $3 \times 3$ matrix of errors for this eclectic trivariate VAR model of credit growths.
} 


\begin{tabular}{llr}
\hline Mean & .0000 & $-.7891 \mathrm{E}-4$ \\
Mean Absolute & .0070398 & $.7891 \mathrm{E}-4$ \\
Mean Sum Squares & $.9808 \mathrm{E}-4$ & $.6227 \mathrm{E}-8$ \\
Root Mean Sum Squares & .0099034 & $.7891 \mathrm{E}-4$ \\
\hline
\end{tabular}

Table 17. Multivariate Dynamic Forecasts for the Level of DLCGER

Based on 173 observations from 1971Q4 to 2014Q4. Order of VAR = 7

List of variables included in the unrestricted VAR: DLCUSA, DLCJAP, DLCGER

List of deterministic and/or exogenous variables: CONST, D08

Observation Actual Prediction Error

2015Q1 $\quad .020802 \quad-.0037629 \quad .024565$

Summary Statistics for Residuals and Forecast Errors

\begin{tabular}{lcc}
\hline \multicolumn{2}{c}{ Estimation Period } & Forecast Period \\
1971Q4 to 2014Q4 & 2015Q1 to 2015Q1 \\
\hline Mean & .0000 & .024565 \\
Mean Absolute & .0057709 & .024565 \\
Mean Sum Squares & $.5146 \mathrm{E}-4$ & $.6034 \mathrm{E}-3$ \\
Root Mean Sum Squares & .0071732 & .024565 \\
\hline
\end{tabular}

Last, but not least, commenting upon the results of estimating impulse responses for the effect of a unit shock to the US, Japan and German, credit growth equation, we get only a small impact on the credit growths of the other two economies and, again, this effect dies out relatively quickly with the forecast horizon. The following figures (7 \& 8) for the US, (9 \& 10) for the Japanese and, (11 \& 12) for the German economy, conclude the relatively small impacts respectively, for both orthogonal and generalized impulse responses, for these three leading economies ${ }^{21}$.

\footnotetext{
${ }^{21}$ Numerical values of all the orthogonalized and generalized impulse responses to one SE shock in the corresponding credit growth equations of the DLCUSA, DLCJAP and DLCGER variables, for the unrestricted vector autoregressive model(s) are always available upon request. The same necessary restriction holds for the numerical and graphic residual analysis due to the large space needed for full representation here.
} 
Figure 7:

Orthogonalised Impulse Responses to one SE shock in the equation for DLCUSA

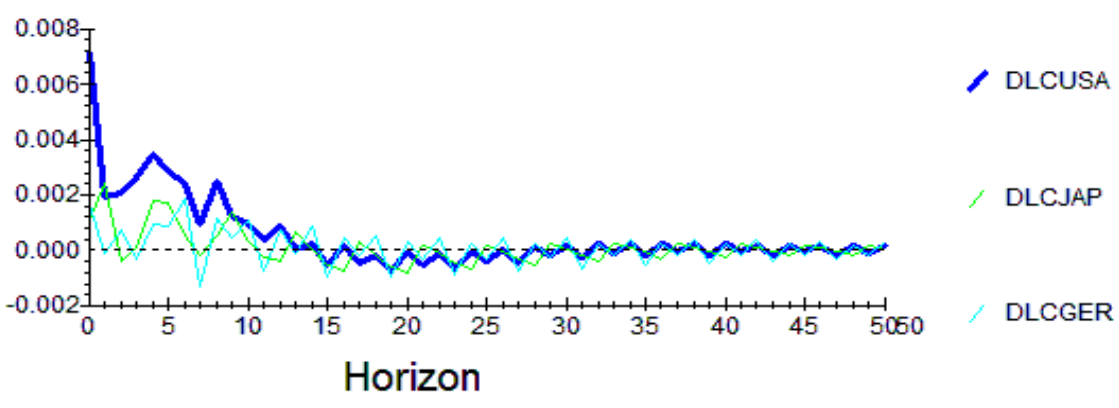

Figure 8:

Generalised Impulse Responses to one SE shock in the equation for DLCUSA

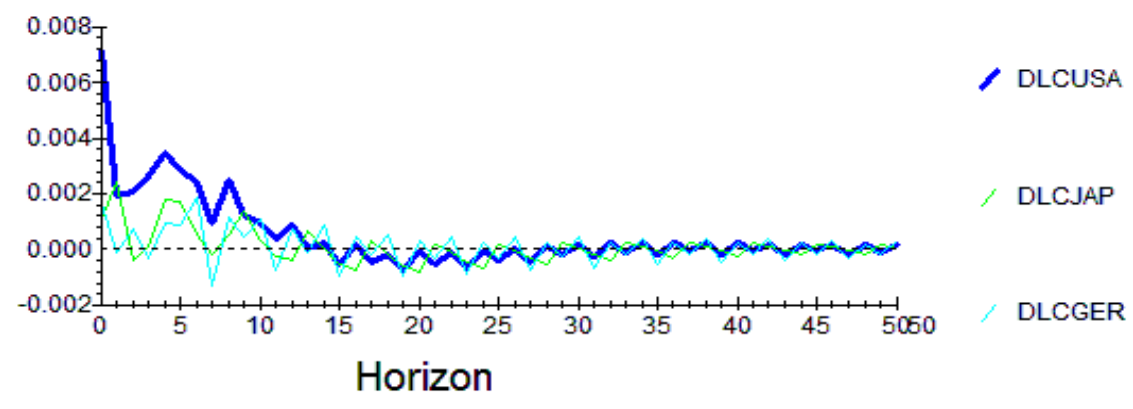

Figure 9:

Orthogonalised Impulse Responses to one SE shock in the equation for DLCJAP

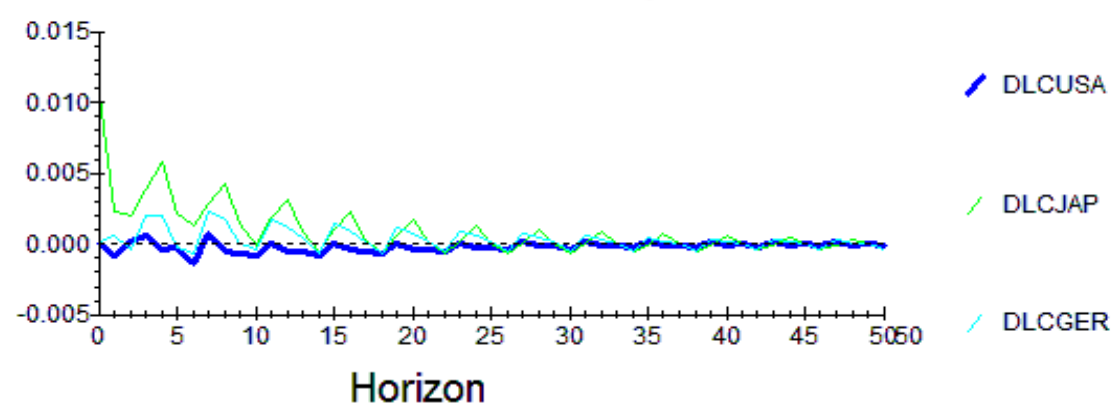


Figure 10:

Generalised Impulse Responses to one SE shock in the equation for DLCJAP

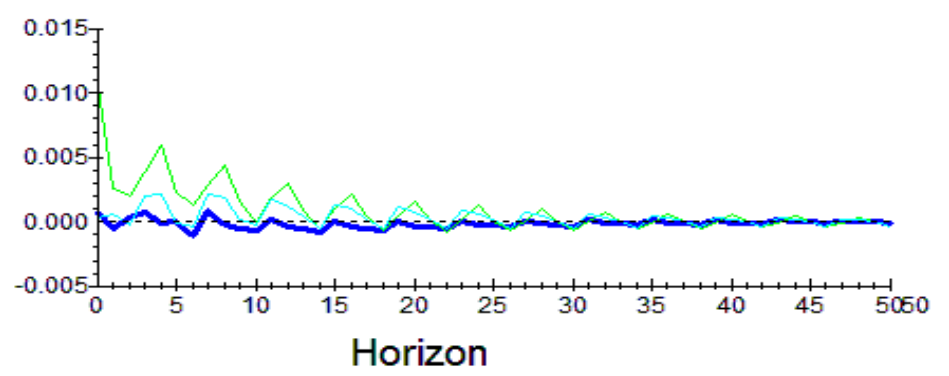

DLCUSA

DLCJAP

DLCGER

Figure 11:

Orthogonalised Impulse Responses to one SE shock in the equation for DLCGER

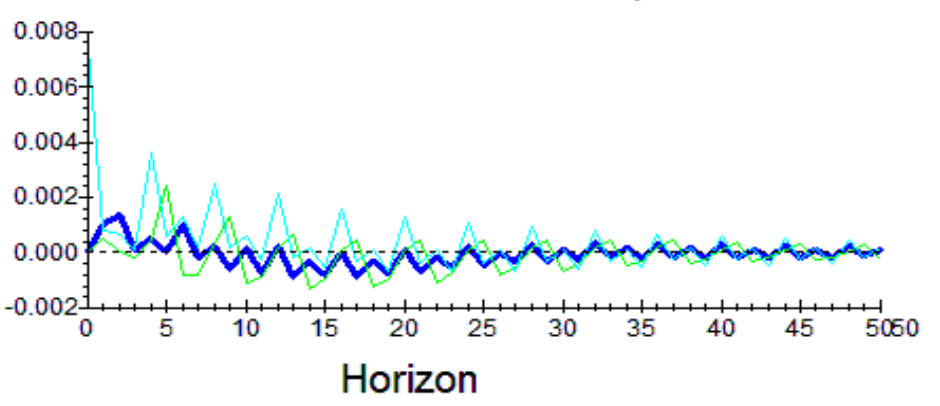

DLCUSA

DLCJAP

DLCGER

Figure 12:

Generalised Impulse Responses to one SE shock in the equation for DLCGER

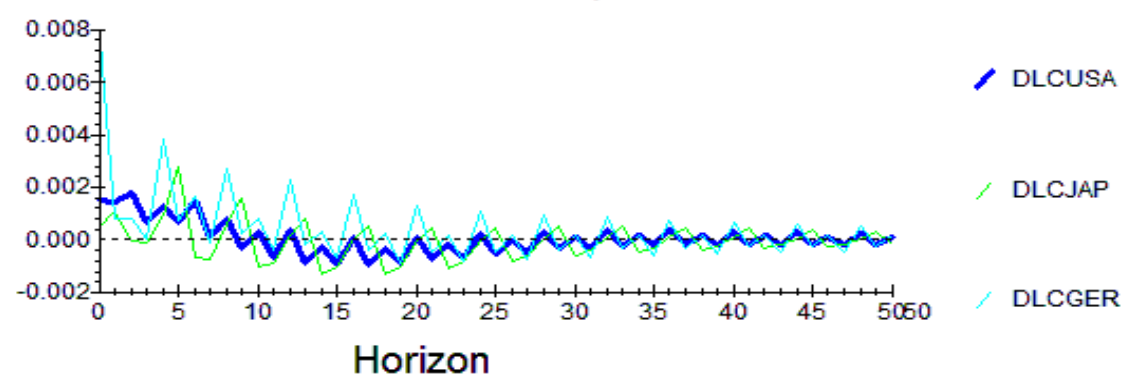




\section{Conclusions}

The purpose of this paper is to contribute to the empirical investigation of the international transmission of credit cycles shocks, based upon an eclectic selection of three special and highly advanced economies that lead capitalism globally; i.e. the US, Japanese and German, whose central banks' role is justified as prominent. Applying classic VAR analysis, intentionally for its directness and clear interpretation, we provide original evidence, employing the most recent, statistically complete and comparable, official BIS credit supply data, from 1970(Q1) up to 2015(Q1), thus linking globally significant financial crises of the past and the present. In fact, we test for global transmissions (and origins) of credit shocks across the USA, Germany and Japan, thus providing significant evidence with respect to our understanding of the global transmission of monetary shocks ( $\mathrm{CE}$ and $\mathrm{QE}$ ), especially now, in the wake of a credit-driven global financial crisis of our time. Our main focus is on the impact of global credit supply shocks - structural breaks, purposely and initially ${ }^{22}$.

Thus, comparing the estimated system covariance matrix of errors for 1973 vs. the 2008 year (tables (6) vs. (14)); that is, comparing the case of the oil price crisis vs. the recent financial crisis years, we can conclude that a higher covariance comovement proportion, based upon the estimated system covariance matrix of errors, applies in the case of the 2008 vs. the 1973 credit growth repercussions, among the three advanced and globally leading economies of the US, Japan and Germany.

Additionally, if there are any significant transmissions of credit shocks among these three economies, during the 70's and after the historic abandonment of the Bretton Woods system and next during the first decade of the $21^{\text {st }}$ century and the still ongoing global financial crisis, it seems that these transmissions are going from one leading economy to the other two. Thus, we face significant statistical evidence that global financial crises, as well as credit supply shocks in particular, in economies that lead capitalism globally, affect each other seriously.

Essentially, if international credit cycles are due to common sources, then the contemporaneous correlation among innovations should be high and there should be little evidence of Granger causality from any two variable block to the remaining variable. Consequently, the credit data confirm more the presence of an international credit cycle, in the sense that credit growth rates in three leading economies in particular move together over time, but the size of the co-movements is not overwhelming; even though it is relatively higher during the 2008 financial crisis than before, a fact that shows increased financial globalization characteristics, along with international banking and financial repercussions among these leading

\footnotetext{
${ }^{22}$ A second step further analysis, incorporating additional macro-economic variables, while taking into account more complex cyclicalities alongside structural variation, could be to build e.g. upon Hecq, Palm and Urbain (2000), but this scope goes beyond our main focus here.
} 
economies. Moreover, Granger causality tests indicate that there appears to be some noticeable evidence of credit transmission.

Additionally, contemporaneous correlation of credit shocks, as a crucial aspect of the international transmission of credit shocks, remains questionable, thus requiring still further detailed evidence.

Quite satisfactory modeling structure, through this particular VAR application, is verified, although for only one step ahead short-run forecasts of credit growths, in this experiment. Indeed, the VAR's model linearity is very transparent and, it is in fact analytically tractable so much that this qualification remains substantial for the interpretation of our results here. Finally, the effect of a unit shock to the credit growth of each specific country in this analysis seems to have a relatively small impact on the credit growths of the other two countries. More so, we verify, through impulse response analysis, that US credit supply shocks have a stronger effect upon the Japanese and German credit supply variable; whereas, the opposite impact of the Japanese and German to the US tends to be weaker, for both the 1973 and most significantly the 2008 financial crisis years ${ }^{23}$.

Under these conditions, the role in decision making and monetary responsibilities of the central banks, in a world of asymmetries of information and complex financial innovations with global repercussions, is most crucial, for the world leading economies. Further so, that this crucial issue of international credit cycles transmissions affecting global financial stability and control, among specific leading economies that guide global capitalism, needs still much further econometric and/or system structure analyses is beyond any doubt.

\section{References}

Athanasenas, A.L. 2010. Credit, income and causality: a contemporary cointegration analysis. European Journal of Operations Research, 201, pp: 194-205.

BBC NEWS. 2015. ECB unveils massive QE boost for Eurozone", Jan $22^{\text {nd }}$.

Bank of Japan. 2010. New procedures for money market operations and monetary easing.

Bank of Japan. 2014. www.boj.or.jp/en/announcements/release_2014/k141031a.pdf

${ }^{23}$ This fact comes in line with previous substantial research by Eickmeier and Ng (2011), Helbling et. al., (2011) and Fadejeva et. al., (2017), despite the FAVAR and GVAR weakness as modeling schemes with respect to the bilateral exposure weights on multi-country variables, that are typically chosen on loosely theoretical or intuitive grounds (See, in particular, Eickmeier and $\mathrm{Ng}(2011))$, and the impulse response functions regarding total credit convergence (See, in particular, Fadejeva et. al. (2017). What is also crucial is that the Eickmeier and $\mathrm{Ng}$ (2011) research data time span is limited to the 1983 - 2009 period only; whereas, the Fadejeva et. al. (2017) research data time span is limited to the 1995 2013 period as well, both not including the crucial 1970's crisis years with statistically uniquely comparable (BIS) credit data, as we applied purposely in this research. 
Bernanke, S.B. 1983. Non-monetary effects of the financial crisis in the propagation of the Great Depression. American Economic Review, pp: 257-276.

Bernanke, S.B., James, H. 1991. The Gold standard, deflation, and financial crisis in the Great Depression: an international comparison. Financial Markets and Financial Crises, (ed) R. G. Hubbard. University of Chicago Press for NBER, Chicago.

Brunner, K., Meltzer, H. 1988. Money and credit in the monetary transmission Process. American Economic Review, 78, pp: 446-451.

Busch, U., Scharnagl, M., Scheithauer, J. 2010. Loan supply in Germany during the financial crisis. Discussion Paper Series 1: Economic Studies No 05/2010, Deutsche Bundesbank, Eurosystem.

Deutsche Bundesbank. 2009. Developments in lending to the German private sector during the global financial crisis. Monthly Report 61(9), pp: 15-32.

De Grauwe, P. 2015. Quantitative easing and the euro zone. The sad consequences of the fear of QE. The Economist, Jan. $21^{\text {st }} 2015$.

Eickmeier, S., Ng, T. 2011. How do credit supply shocks propagate internationally? A GVAR approach. Discussion Paper Series 1: Economic Studies No 27/2011, Deutsche Bundesbank, Eurosystem.

European Parliament. 2012. Central banks in times of crisis, The FED versus the ECB. Directorate General for Internal Policies, Policy Department A: Economic and Scientific.

Fadejeva, L., Feldkircher, M., Reininger, T. 2017. International spillovers from euro area and US credit and demand shocks: a focus on emerging Europe. Journal of International Money and Finance, 70, pp: 1-25.

Fawley, B.W., Neely, C. 2013. Four stories of quantitative easing. Fed Res Bank of St. Louis Review, Jan/Feb 95(1), pp: 51-88.

FederalReserve.Gov. 2009. Credit easing versus quantitative easing. Jan $13^{\text {th }}$.

Feldstein, M. 2011. Quantitative easing and America's economic rebound. Project-syndicate.org., Project Syndicate.

Hecq, A., Palm, F. C., Urbain, J-P. 2000. Permanent - transitory decomposition in VAR models with cointegration and common cycles. Oxford Bulletin of Economics and Statistics, 62, 4, pp: 511-532.

Helbling, T., Huidrom, R., Kose, M., Otrok, C. 2011. Do credit shocks matter? A global perspective. European Economic Review, 55, pp: 340-353.

Holtham, G. 1988. Foreign responses to US macroeconomic policies. Empirical Macroeconomics for Interdependent Economies, (ed) R. C. Bryant et al. Washington D.C., pp: 267-284.

Kashyap, K.A., Stein, C. 1994. Monetary policy and bank lending. NBER, Studies in Business Cycles 29, pp: 221-256.

Klyuev, V., de Imus, P., Srinivasan, K. 2009. Unconventional choices for unconventional times: credit and quantitative easing in advanced economies. IMF Staff Position Note SPN/09/27, Nov 7.

Koop, G., Pesaran, M., Potter, S. 1996. Impulse response analysis in nonlinear multivariate models. Journal of Econometrics, 74, pp: 119-147.

Krugman, P. 2014. Earth to Ben Bernanke. The New York Times, April 24.

Neely, C.J. 2014. Lessons from the taper tantrum), Economic Synopses, Federal Reserve Bank of St. Louis, Number 2.

Pesaran, H., Shin, Y. 1997. Generalized impulse response analysis in linear multivariate models. Unpublished manuscript, Cambridge University. 
Sims, C. 1972. Money, income, and causality. American Economic Review, 62(4), pp: 540-552.

Sims, C. 1980. Macroeconomics and reality. Econometrica, 48, pp: 1-48.

Sims, C., 1981. An autoregressive index model for the US 1948-1975. Large Scale Econometric Models, J. B. Ramsey. N. Holland, The Netherlands.

Sørensen, K., Marqués, Ibáñez, D., Rossi, C. 2009. Modeling loans to nonfinancial corporations in the euro area. Working Paper No. 989, ECB.

Trautwein, M. 2000. The credit view, old and new. Journal of Economic Surveys, 14(2), pp: 155-189.

Wolfers, J. 2014. The Fed has not stopped trying to stimulate the economy. The New York Times, October 29th.

Wagner, H. 2010. The causes of the recent financial crisis and the role of central banks in avoiding the next one. International Economics and Economic Policy, 7, pp; 63-82. doi: 10.1007/s10368-010-0154-z.

Worms, A. 2003. Interbank relationships and the credit channel in Germany. Empirica, 30, pp: 179-198. 